\title{
Rhamnetin induces apoptosis in human breast cancer cells via the $\mathrm{miR}-34 \mathrm{a} /$ Notch-1 signaling pathway
}

\author{
LAN LAN $^{1}$, YUE WANG $^{2}$, ZHANYU PAN $^{1}$, BIN WANG $^{1}$, ZHENSONG YUE $^{1}$, \\ ZHANSHENG JIANG ${ }^{1}$, LING LI ${ }^{1}, \mathrm{CONG} \mathrm{WANG}^{1}$ and HONGMEI TANG ${ }^{3}$ \\ ${ }^{1}$ Department of Integrated Traditional Chinese and Western Medicine, Tianjin Medical University Cancer Institute and Hospital, \\ National Clinical Research Center for Cancer, Tianjin 300060; ${ }^{2}$ Department of Immunology, School of Medicine, Nankai \\ University, Tianjin 300071; ${ }^{3}$ College of Life Science, Hebei United University, Tangshan, Hebei 063000, P.R. China
}

Received June 4, 2016; Accepted March 19, 2018

DOI: $10.3892 / \mathrm{ol} .2018 .9575$

\begin{abstract}
The present study aimed to investigate whether rhamnetin induced apoptosis in human breast cancer cells and the underlying molecular mechanism of this anti cancer effect. The treatment of MCF-7 cells with rhamnetin was able to significantly inhibit cell proliferation and induce caspase-3/9 activity in a dose- and time-dependent manner, compared with untreated cells. In addition, treatment with rhamnetin was able to significantly promote the expression of p53 protein and microRNA (miR-)34a compared with untreated cells. The treatment with rhamnetin also suppressed the expression of Notch1 protein in MCF-7 cells compared with untreated cells. Subsequently, miR-24a expression was promoted in rhamnetin-treated MCF-7 cells using a miR-34a plasmid. The overexpression of miR-34a was able to significantly inhibit cell viability and induce caspase-3/9 activity in MCF-7 cells following treatment with rhamnetin. Furthermore, the overexpression of miR-34a was able to significantly promote the expression of $\mathrm{p} 53$ protein and miR-34a, and suppress the expression of Notch1 protein in rhamnetin-treated MCF-7 cells. Therefore, the results of the present study demonstrated that rhamnetin induced apoptosis in human breast cancer cells via the miR-34a/Notch-1 signaling pathway.
\end{abstract}

\section{Introduction}

Breast cancer is the most common type of malignancy in women, of which the incidence and mortality rates rank first in cancer cases in females worldwide (1). In spite of early treatment, $\sim 30 \%$ patients with breast cancer will experience relapse and metastasis (1). For patients diagnosed with

Correspondence to: Dr Lan Lan, Department of Integrated Traditional Chinese and Western Medicine, Tianjin Medical University Cancer Institute and Hospital, National Clinical Research Center for Cancer, 24 Binshui Road, Tianjin, Hebei 300060, P.R. China

E-mail: ljxyvrv8950@126.com

Key words: rhamnetin, breast cancer, microRNA 34a, Notch-1 metastatic breast cancer, the conventional treatment typically controls the development of the disease effectively at first; however, over time, the majority of patients will deteriorate (2). To decrease mortality rates and develop novel therapeutic strategies, the molecular biological characteristics of breast cancer cells require further investigation.

microRNA (miRNA/miR), a small non-coding RNA molecule between 21 and 23 nucleotides in length, serves important regulatory functions in a number of types of biological processes, including inflammation, apoptosis and autophagy (3). miRNAs may inhibit the expression of proteins or induce mRNA degradation by complementary base pairing with the mRNA of target genes at specific binding sites, so as to participate in gene regulation (4). miRNAs are able to regulate cancer-associated genes, serving possibly as a cancer suppressor gene (5). In various tumor tissues, including breast, colon and liver cancer tissues, decreased expression of miRNA shas been observed (6); therefore, regulating the levels of miRNA in cancer cells, particularly in cancer stem cells, may be used to identify a novel treatment strategy.

The miR-34 family includes miR-34a, $-34 b$ and $-34 c(7,8)$. Previous studies have demonstrated that the cancer suppressor gene p53 directly induced the expression of miR-34, which promoted apoptosis and induced cell cycle arrest $(7,8)$. miR-34a serves an important function in the proliferation, invasion and metastasis of breast cancer cells $(9,10)$. Previous studies have revealed that miR-34a may inhibit proliferation of pancreatic and stomach cancer stem cells $(9,10)$.

The involvement of the Notch1 signaling pathway in tumor chemoresistance has been gaining increasing attention. A previous study demonstrated that the inhibition of Notch1 in prostate cancer may increase the sensitivity of cells to docetaxel. Furthermore, oxaliplatin may induce the Notch1 signaling pathway in colon cancer (11). In addition, a significantly increased expression of Notch1 was observed in the patients with cisplatin resistance in ovarian cancer, cervical cancer, head and neck squamous cell carcinoma tumors (12). Silencing Notch1 significantly increased the toxic effect of cisplatin on tumor cells, such as breast cancer, lung cancer or liver cancer (12).

The Notch signaling pathway has been conserved throughout evolution and serves an important function in 
embryonic development, organ maturation and tumorigenesis (13). Notch1 is a Notch receptor that is associated with the occurrence, metastasis and drug resistance of breast cancer (13). A previous study revealed that Notch1 serves an important function in maintaining self-renewal and regulating the differentiation of breast cancer stem cells (13). Notch1 a target gene of miR-34a; therefore, the miR-34a/Notch1 signaling pathway may serve functions in the cell proliferation of breast cancer cells and stem cells $(14,15)$.

Isorhmnetin and glycosides are present in a variety of plants, including sea buckthorn, Salix matsudana, orientin, Gynostemma yixingense, camel thorn and wolfberry (16). Sea buckthorn is rich in rhamnetin, which is one of the main monomers in sea buckthorn, and is typically used as a standard for the determination of flavonoid content (17). Previous studies have identified that rhamnetin exhibited multiple cardiovascular prevents myocardial ischemia and ischemia, angina, arrhythmia, oxygen free radicals and serum cholesterol $(18,19)$. However, to the best of our knowledge, the tumor inhibitory effect of rhamnetin as a monomer remains unknown. Rhamnetin exhibits strong anti-tumor effects (20). The present study aimed to investigate whether rhamnetin induced apoptosis in human breast cancer cells and the underlying molecular mechanism of this anticancer effect.

\section{Materials and methods}

Cells and materials. MCF-7 breast cancer cell lines were obtained from the School of Medicine, Nankai University (Tianjin, China) and Dulbecco's modified Eagle's medium (DMEM; Invitrogen; Thermo Fisher Scientific, Inc., Waltham, MA, USA), supplemented with $10 \%$ fetal bovine serum (Invitrogen; Thermo Fisher Scientific, Inc.) at $37^{\circ} \mathrm{C}$ in an atmosphere containing $5 \% \mathrm{CO}_{2}$.

MTT proliferation assay. The MCF-7 cells cultured with DMEM were subcultured into 96-well culture microplates $\left(1 \times 10^{4}\right.$ cells/well) at $37^{\circ} \mathrm{C}$ in an atmosphere containing $5 \%$ $\mathrm{CO}_{2}$. After $24 \mathrm{~h}$ incubation, the medium was discarded and replaced with $100 \mu \mathrm{l}$ fresh DMEM containing $0,5,10,15$, $25 \mu \mathrm{M}$ rhamnetin and incubated for 24,48 and $72 \mathrm{~h}$ at $37^{\circ} \mathrm{C}$. Subsequently, $20 \mu \mathrm{l}$ MTT test solution was added to each well. After $4 \mathrm{~h}$ incubation at $37^{\circ} \mathrm{C}$ in an atmosphere containing $5 \%$ $\mathrm{CO}_{2}$, the medium was discarded and $150 \mu$ l dimethyl sulfoxide was added to each well. After $20 \mathrm{~min}$ incubation in an incubator at $37^{\circ} \mathrm{C}$, absorbance was determined at $490 \mathrm{~nm}$ on an ELISA reader (Molecular Devices, LLC, Sunnyvale, CA, USA).

Caspase-3/9 activity. The cultured MCF-7 cells with DMEM were subcultured into 6-well culture microplates $\left(1 \times 10^{6}\right.$ cells/well $)$ at $37^{\circ} \mathrm{C}$ in an atmosphere containing $5 \%$ $\mathrm{CO}_{2}$. After $24 \mathrm{~h}$ incubation, the medium was discarded and replaced with $100 \mu \mathrm{l}$ fresh DMEM with $0,5,10,15$ and $25 \mu \mathrm{M}$ rhamnetin for $48 \mathrm{~h}$ at $37^{\circ} \mathrm{C}$. MCF-7 cells were lysed using the radioimmunoprecipitation assay (RIPA) lysis buffer (Beyotime Institute of Biotechnology, Haimen, China) for $30 \mathrm{~min}$ at $4^{\circ} \mathrm{C}$. Total protein concentration was quantitated using the BCA method (Beyotime Institute of Biotechnology), and $20 \mu \mathrm{g}$ total protein was incubated with Ac-DEVD-pNA (Caspase-3; C1116, Beyotime Institute of Biotechnology) or

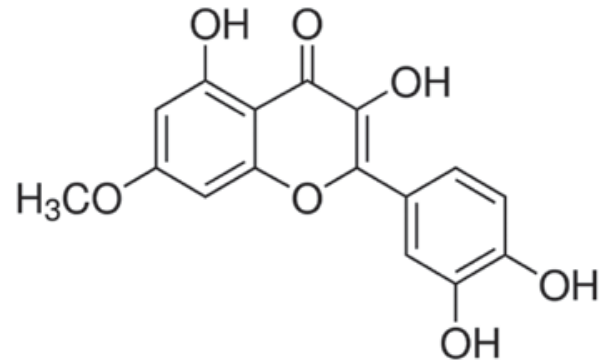

Figure 1. Chemical structure of rhamnetin.

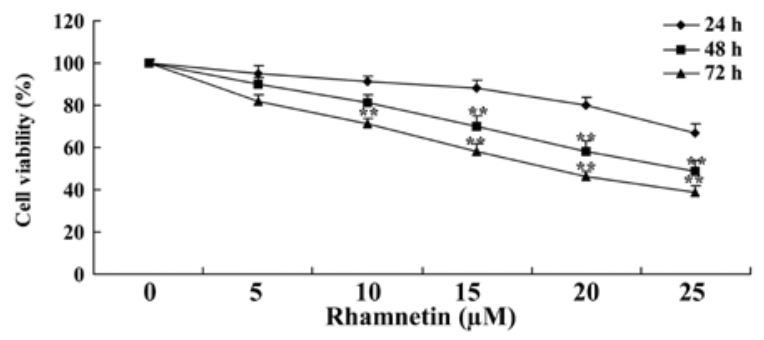

Figure 2. Rhamnetin suppresses the viability of human breast cancer MCF-7 cells. ${ }^{* *} \mathrm{P}<0.01$ vs. $0 \mu \mathrm{M}$ rhamnetin.

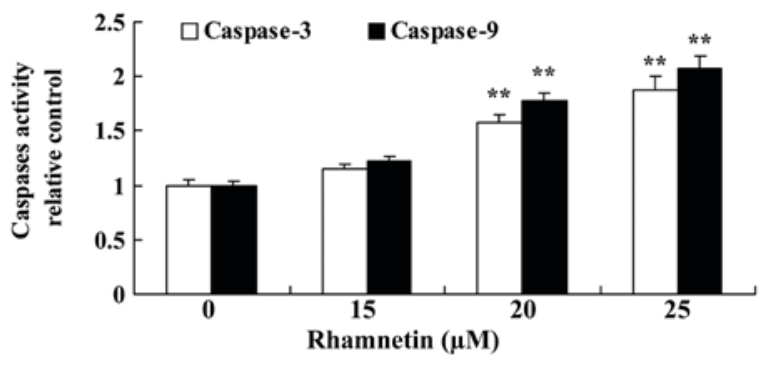

Figure 3. Rhamnetin induces caspase- $3 / 9$ activity in MCF-7 cells. ${ }^{* *} \mathrm{P}<0.01$ vs. $0 \mu \mathrm{M}$ rhamnetin.

Ac-LEHD-pNA (Caspase-9; C1158, Beyotime Institute of Biotechnology). After $2 \mathrm{~h}$ incubation at $37^{\circ} \mathrm{C}$, the absorbance was determined at $405 \mathrm{~nm}$ on an ELISA reader (Molecular Devices, LLC).

Western blot analysis. The cultured MCF-7 cells with DMEM were subcultured into 6-well culture microplates $\left(1 \times 10^{6}\right.$ cells/well $)$ at $37^{\circ} \mathrm{C}$ in an atmosphere containing $5 \%$ $\mathrm{CO}_{2}$. After $24 \mathrm{~h}$ incubation, the medium was discarded and replaced with $100 \mu \mathrm{l}$ fresh DMEM with $0,5,10,15$ and $25 \mu \mathrm{M}$ rhamnetin for $48 \mathrm{~h}$ at $37^{\circ} \mathrm{C}$. MCF-7 cells were lysed using with RIPA lysis buffer (Beyotime Institute of Biotechnology) for $30 \mathrm{~min}$ at $4^{\circ} \mathrm{C}$. Total protein concentration was quantified using the BCA method (Beyotime Institute of Biotechnology). Subsequently, $50 \mu \mathrm{g}$ total protein concentration was separated using SDS-PAGE (8-12\% gels) and electro transferred to polyvinylidene fluoride membranes (EMD Millipore, Billerica, MA, USA). The membranes blocked with 5\% non-fat milk in TBST for $1 \mathrm{~h}$ at $37^{\circ} \mathrm{C}$ and immunoblotted with primary antibodies against p53 (sc-71817, dilution, 1:500; Santa Cruz Biotechnology, Inc., Dallas, TX, USA), Notch-1 (sc-71719, dilution, 1:500; Santa Cruz Biotechnology, Inc.) and GAPDH 
A

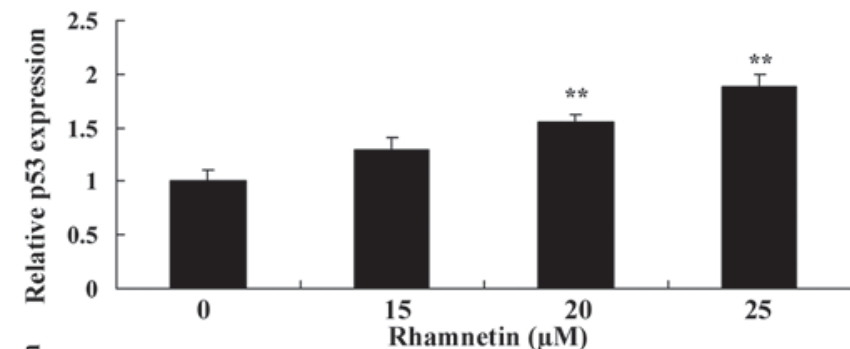

$\mathrm{B}$

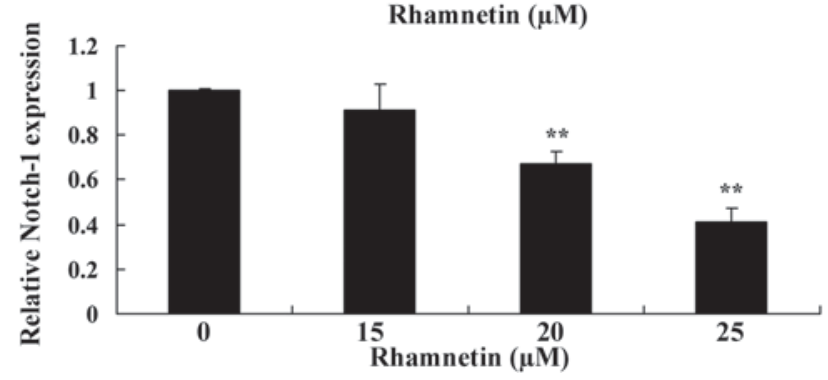

$\mathrm{C}$

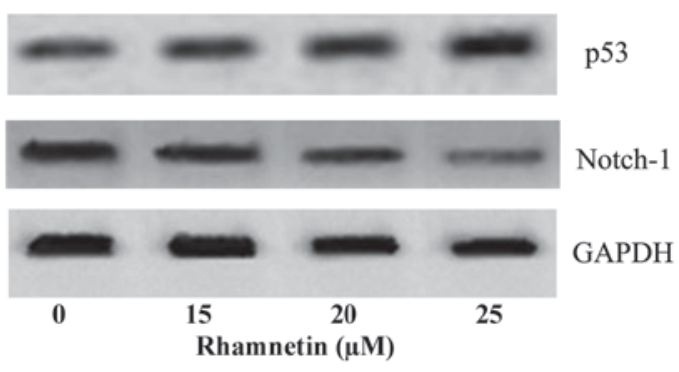

Figure 4. Rhamnetin treatment affects p53 and Notch-1 expression in MCF-7 cells. The expression of (A) p53 was increased and (B) Notch-1 was decreased following rhamnetin treatment in MCF-7 cells as indicated by western blot analysis. ${ }^{* *} \mathrm{P}<0.01 \mathrm{vs} .0 \mu \mathrm{M}$ rhamnetin.

(sc-51631, dilution, 1:1,000; Santa Cruz Biotechnology, Inc.) overnight at $4{ }^{\circ} \mathrm{C}$, followed by incubation with anti-rabbit secondary antibodies (sc-2004, dilution, 1:5,000; Santa Cruz Biotechnology, Inc.) for $1 \mathrm{~h}$ at $37^{\circ} \mathrm{C}$ following washing for 15 min using TBSTween-20. The membranes were visualized using an enhanced chemiluminescence kit (GE Healthcare, Chicago, IL, USA).

Reverse transcription-quantitative ( $R T$-qPCR). TRIzol reagent (Invitrogen; Thermo Fisher Scientific, Inc.) was used to isolate total RNA from MCF-7 cells. A total of $2 \mu \mathrm{g}$ RNA was reverse transcribed into cDNA using the Takara RNA PCR set (Takara Bio, Inc., Otsu, Japan) at $37^{\circ} \mathrm{C}$ for $30 \mathrm{~min}$ and $85^{\circ} \mathrm{C}$ for $1 \mathrm{~min}$ according to the manufacturer's protocol. qPCR was performed using the StepOne and StepOnePlus Real-Time PCR system (Applied Biosystems; Thermo Fisher Scientific, Inc.). The primer sequences for miR-34a were as follows: Forward, 5'-TGGCAGTGTCTTAGCTGGTTGT-3'; and reverse, 5'-GGCAGTATACTTGCTGATTGCTT-3'. The primer sequences for U6 were as follows: Forward, 5'-CTC GCTTCGGCAGCACA-3'; and reverse, 5'-AACGCTTCA CGAATTTGCGT-3'. PCR was performed for 40 cycles of $95^{\circ} \mathrm{C}$ for $30 \mathrm{sec}$ and $60^{\circ} \mathrm{C}$ for $30 \mathrm{sec}$. The expression relative was determined using the $2^{-\triangle \Delta C q}$ method relative to U6 (21).

Plasmid construction and transfection. miR-34a mimics (5'-UGGCAGUGUCUUAGCUGGUUGU-3') and negative control miRNA mimic (5'-CCCCCCCCCCCCCCC-3') were purchased from Shanghai GeneChem Co., Ltd. (Shanghai, China). A total of $100 \mathrm{ng}$ of miR-34a mimics and the negative control miRNA mimic were used to transfect MCF-7 cells using Lipofectamine ${ }^{\circledR} 2000$ transfection reagent (Invitrogen; Thermo Fisher Scientific, Inc.). Following $4 \mathrm{~h}$ of transfection, old DMEM was substituted with new DMEM without fetal bovine serum and was added into the cell.

Statistical analysis. Data are expressed as the mean \pm standard error of the mean using SPSS 17.0 (SPSS, Inc., Chicago, IL,

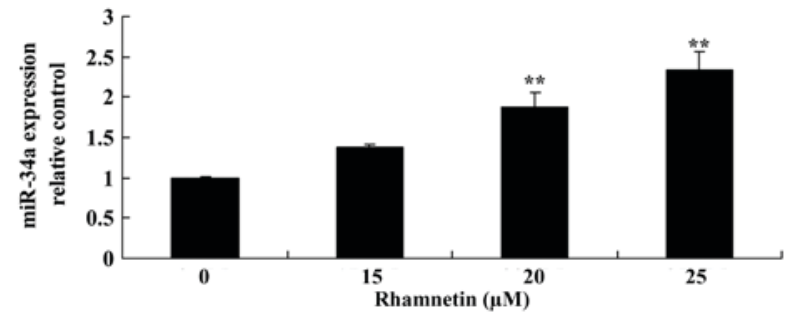

Figure 5. Rhamnetin promotes miR-34a expression in MCF-7 cells. ${ }^{* *} \mathrm{P}<0.01$ vs. $0 \mu \mathrm{M}$ rhamnetin. miR, microRNA.

USA). One-way analysis of variance was used for evaluating the statistical significance between groups followed by the Bonferroni post hoc test. $\mathrm{P}<0.05$ was considered to indicate a statistically significant difference.

\section{Results}

Rhamnetin suppresses the proliferation of MCF-7 human breast cancer cells. The chemical structure of rhamnetin is presented in Fig. 1. First, the anti-cancer effects of rhamnetin on the cell viability of MCF-7 cells were examined. As presented in Fig. 2, rhamnetin suppressed the cell viability of human breast cancer cells MCF-7 in a time- and dosedependent manner. When MCF-7 cells were treated with various $10-25 \mu \mathrm{M}$ rhamnetin for $72 \mathrm{~h}$, or $15-25 \mu \mathrm{M}$ rhamnetin for $48 \mathrm{~h}$, the proliferation of MCF-7 cells was significantly decreased compared with the untreated cells. Therefore, these findings indicated that treatment with rhamnetin was able to suppress the proliferation of human breast cancer MCF-7 cells.

Rhamnetin induces caspase-3/9 activity in MCF-7 cells. Subsequently, the effect of rhamnetin on caspase-3/9 activity in MCF-7 cells was examined using various concentrations of rhamnetin $(0,15,20$ and $25 \mu \mathrm{M})$ ELISA. The results of the present study indicated that 20 and $25 \mu \mathrm{M}$ rhamnetin were able to significantly increase the caspase-3/9 activity in MCF-7 

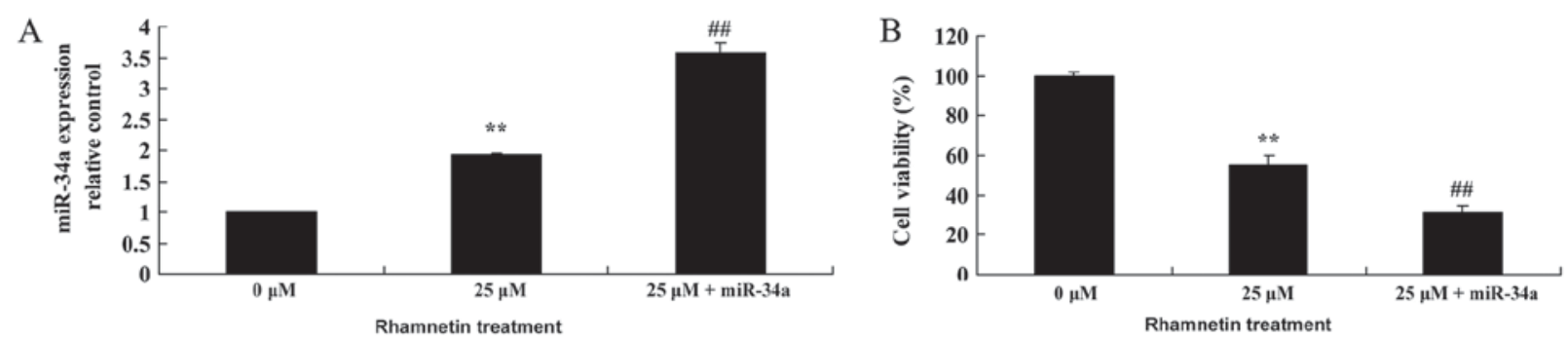

Figure 6. Activation of miR-34a affects the proliferation of MCF-7 cells that were treated with rhamnetin. (A) Treatment with $25 \mu \mathrm{M}$ rhamnetin increased miR-34a expression, and overexpression of miR-34a with $25 \mu \mathrm{M}$ rhamnetin treatment induced this effect further. (B) Treatment with $25 \mu \mathrm{M}$ rhamnetin decreased the viability of MCF-7 cells, and overexpression of miR-34a with $25 \mu \mathrm{M}$ rhamnetin induced this effect further. ${ }^{* *} \mathrm{P}<0.01$ vs. $0 \mu \mathrm{M}$ rhamnetin; ${ }^{\# \#} \mathrm{P}<0.01$ vs. $25 \mu \mathrm{M}$ rhamnetin. $0 \mu \mathrm{M}$, control; $25 \mu \mathrm{M}+$ miR-34a, $25 \mu \mathrm{M}$ rhamnetin with miR-34a plasmid; miR-34a, microRNA 34a.

cells in a dose-dependent manner compared with the untreated cells (Fig. 3).

Rhamnetin induces p53 protein expression in MCF-7 cells. To investigate whether apoptosis is promoted following rhamnetin treatment in $\mathrm{MCF}-7$ cells, p53 protein expression was examined using western blot analysis. As presented in Fig. 4, p53 expression was significantly increased in MCF-7 cells compared with the untreated cells following the treatment of MCF-7 cells with 20 and $25 \mu \mathrm{M}$ rhamnetin for $48 \mathrm{~h}$.

Rhamnetin suppresses Notch-1 protein expression in MCF-7 cells. The anti-effect mechanism of rhamnetin on Notch-1 expression in MCF-7 cells was evaluated; 20 and $25 \mu \mathrm{M}$ rhamnetin were able to significantly decrease Notch-1 expression in MCF-7 cells compared with the untreated cells (Fig. 4).

Rhamnetin promotes miR-34a expression in MCF-7 cells. To evaluate the anti-effect mechanism of rhamnetin in MCF-7 cells, miR-34a expression was determined using RT-qPCR. miR-34a expression in MCF-7 cells was significantly increased following treatment with 20 and $25 \mu \mathrm{M}$ rhamnetin for $48 \mathrm{~h}$ compared with the untreated cells (Fig. 5).

Overexpression of miR-34a inhibits the proliferation of MCF-7 cells following treatment with rhamnetin. According to the previous results in the present study, it was hypothesized that miR-34a may mediate the anti-cancer effects of rhamnetin in MCF-7 cells. As presented in Fig. 6A, transfection with miR-34a mimics significantly increased miR-34a expression in $\mathrm{MCF}-7$ cells that were treated with rhamnetin $(25 \mu \mathrm{M})$ compared with MCF-7 cells that were treated with $25 \mu \mathrm{M}$ rhamnetin alone. Subsequently, the overexpression of miR-34a significantly inhibited the cell viability of MCF-7 cells compared with the $25-\mu \mathrm{M}$ rhamnetin treatment group (Fig. 6B).

Overexpression of $\mathrm{miR}-34 \mathrm{a}$ increases caspase-3/9 activity in MCF-7 cells following treatment with rhamnetin. The effect of rhamnetin on the activity of caspase-3/9 in MCF-7 cells that were treated by rhamnetin was subsequently examined. As presented in Fig. 7, the overexpression of miR-34a was able to significantly increase caspase-3/9 activity in MCF-7 cells that were treated with $25 \mu \mathrm{M}$ rhamnetin, compared with treatment with $25 \mu \mathrm{M}$ rhamnetin alone.

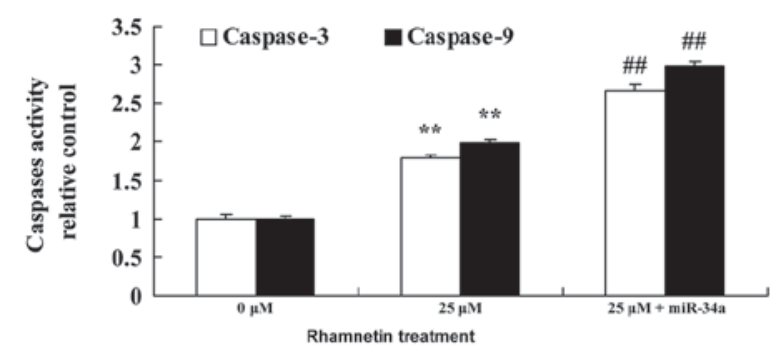

Figure 7. Activation of miR-34a increases caspase-3/9 activity in MCF-7 cells that were treated with rhamnetin. ${ }^{* *} \mathrm{P}<0.01$ vs. $0 \mu \mathrm{M}$ rhamnetin; ${ }^{\# \#} \mathrm{P}<0.01$ vs. $25 \mu \mathrm{M}$ rhamnetin. $0 \mu \mathrm{M}$, control; $25 \mu \mathrm{M}+\operatorname{miR}-34 \mathrm{a}, 25 \mu \mathrm{M}$ rhamnetin with miR-34a plasmid; miR-34a, microRNA 34a.

p53 protein expression increases following overexpression of miR-34 $a$ and rhamnetin treatment. To validate the association between miR-34a and p53, MCF-7 cells were treated with rhamnetin and transfected with miR-34a mimic. Subsequently, p53 protein expression was determined using western blot analysis. The induction of p53 protein expression was significantly increased following overexpression of miR-34a in rhamnetin-treated MCF-7 cells compared with cells that were treated with $25-\mu \mathrm{M}$ rhamnetin alone (Fig. 8).

Overexpression of $m i R-34 a$ and rhamnetin treatment decreases Notch-1 expression. To investigate the association between miR-34a and Notch-1 following the overexpression of miR-34a in MCF-7 cells, Notch-1 protein expression was determined using western blot analysis in MCF-7 cells. The results from the western blot analysis revealed that Notch-1 expression was significantly suppressed by the overexpression of miR-34a in MCF-7 cells that were treated with rhamnetin compared with MCF-7 cells that were treated with $25-\mu \mathrm{M}$ rhamnetin alone (Fig. 8).

\section{Discussion}

Breast cancer is a life-threatening disease for women worldwide, and the advancements in early diagnosis and treatment of breast cancer has markedly reduced mortality rates (22). However, the recurrence, metastasis and resistance to chemotherapy of breast cancer present challenges for treatment (23). Statistics reveal that breast cancer accounts for $\sim 15 \%$ of all cancer-associated mortalities worldwide, and the number of patients 

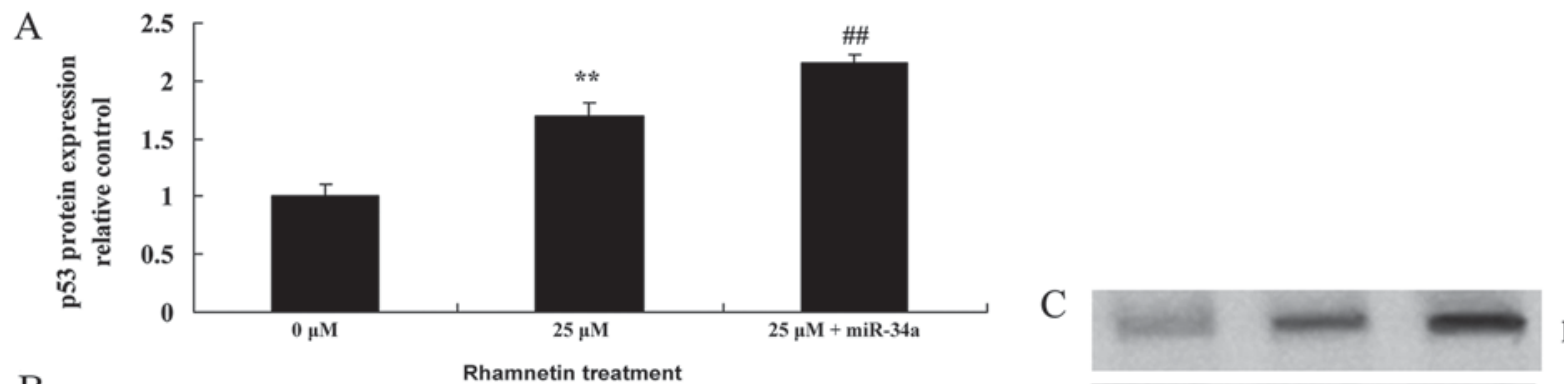

p53
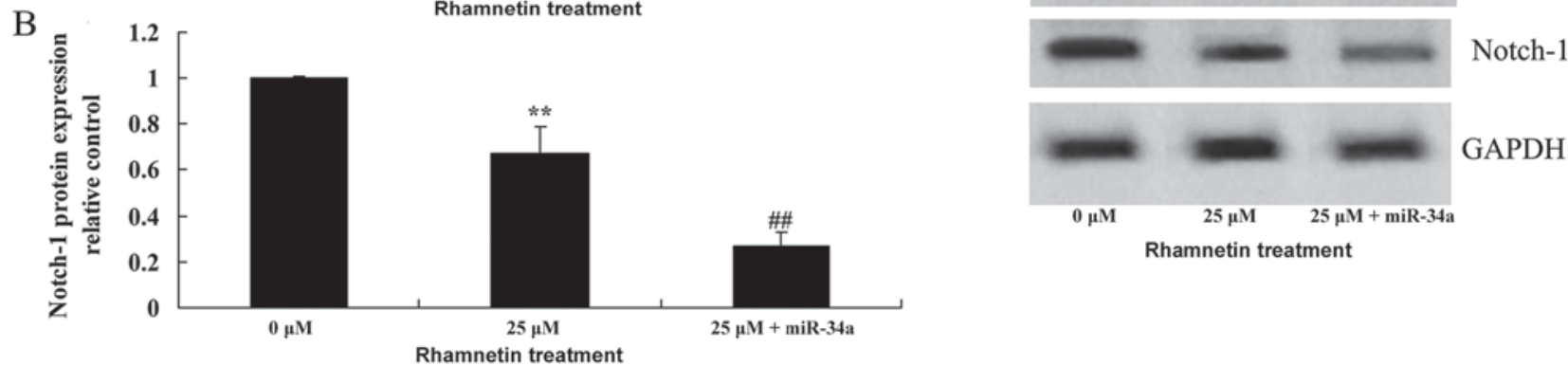

Figure 8. Overexpression of miR-34a affects the expression of p53 and Notch-1 in MCF-7 cells that were treated with rhamnetin. (A) Treatment with $25 \mu \mathrm{M}$ rhamnetin increased p53 expression, and the overexpression of miR-34a and treatment with $25 \mu \mathrm{M}$ rhamnetin induced this effect further. (B) Treatment with $25 \mu \mathrm{M}$ rhamnetin decreased Notch1 expression, and the overexpression of miR-34a with $25 \mu \mathrm{M}$ rhamnetin induced this effect further. (C) Western blots indicating p53 and Notch-1 expression in MCF-7 cells that were treated with rhamnetin and transfected with miR-34a plasmid. ${ }^{* *} \mathrm{P}<0.01$ vs. $0 \mu \mathrm{M}$ rhamnetin; ${ }^{\# \#} \mathrm{P}<0.01$ vs. $25 \mu \mathrm{M}$ rhamnetin. $0 \mu \mathrm{M}$, control; $25 \mu \mathrm{M}+$ miR-34a, $25 \mu \mathrm{M}$ rhamnetin with miR-34a plasmid; miR-34a, microRNA 34a.

with breast cancer is increasing by $>1.3$ million/year $(22,24)$. Therefore, studies that focus on the search for novel and effective diagnostic and treatment methods remain prevalent in breast cancer research. Pieme et al (25) demonstrated that rhamnetin induced mitochondrial-dependent apoptosis and $\mathrm{G}_{0} / \mathrm{G}_{1}$ phase arrest in human leukemia HL- 60 cells. In the present study, it was revealed that treatment with rhamnetin was able to suppress the cell viability of MCF-7 cells and induce caspase-3/9 activity, suggesting that rhamnetin serves an anti-cancer function.

miR-34a is capable of regulating proliferation, apoptosis, invasion and migration of tumor cells by targeting multiple genes, which indicates that it may be more beneficial in gene therapy compared with short-interfering RNA (8). At present, a number of studies have focused on increasing the understanding of the tumor suppressor effects of miR-34a with the aim of improving prognosis for patients (26). It has been identified that nanoparticles may be used to deliver miRNA or the miRNA mimetic into the body effectively. The delivery of the miR-34a mimetic by nanoparticles using intravenous or intratumoral injection method was able to significantly inhibit tumor growth, without serious toxicities or adverse immune reactions, in various cancer types, including breast, prostate, pancreatic cancer and non-small cell lung cancer $(10,26)$.

Kang et al (27) reported that rhamnetin and cirsiliol induce radiosensitization by miR-34a-mediated of p53 and Notch-1. The present study demonstrated that treatment with rhamnetin was able to significantly induce miR-34a expression in MCF-7 cells. Therefore, the upregulation of miR-34a may represent a novel mechanism for the anti-cancer effect of rhamnetin in human breast cancer.

As a downstream target of p53, miR-34a serves an important function in regulating the p53 network. Upregulating miR-34a induced apoptosis and cell cycle arrest, and p53 may enhance this affect by a positive feedback loop that involves the p53-miR-34a-sirtuin 1 signaling pathway (28). In addition, miR-34a is subject to regulation by p53-dependent and p53-independent pathways $(29,30)$. The aforementioned findings suggest that rhamnetin is able to induce p53 protein expression in MCF-7 cells. Therefore, it has been suggested that $\mathrm{p} 53$-associated apoptotic factors are involved in mediating the apoptotic effect of rhamnetin in MCF-7 cells $(29,30)$.

The Notch pathway is an evolutionarily conservative signaling pathway and is associated with cell proliferation, apoptosis, epithelial-mesenchymal transition, and self-renewal and differentiation of stem cells (31). The Notch signaling pathway is activated by the combination of a ligand and a receptor between adjacent cells (32). Following receptor and ligand binding, Notch intracellular domain (NICD) is released by enzyme action and NICD enters the nucleus to activate the transcription of downstream target genes (33). The Notch signaling pathway primarily exhibits tumor-promoting effects, but it has been suggested that its function varies in different types of tumor (34).

The Notch1 pathway is a highly conservative signaling pathway, which is widely expressed in vertebrates and invertebrates, and which serves an important function in embryonic development, organ maturation and tumor development process (35). In mammals, the Notch signaling pathway molecules includes four transmembrane receptors (Notch1-4) and five ligands (delta-like 1, 3 and 4, and jagged-1 and 2). A previous study demonstrated that the activated forms of continuous expression of Notch1 or Notch4 induced the formation of spontaneous mammary tumors in mice, which suggested that activation of the Notch signaling pathway is associated with the occurrence of breast cancer (36). Bioinformatics analysis revealed that Notch1 is a target gene of miR-34a, suggesting that Notch1 may serve a function in the regulation of miR-34a in breast cancer (13). The results of the present study identified that the overexpression of miR-34a was able to significantly 
promote the expression of $\mathrm{p} 53$ protein and suppress the expression of Notch1 protein in MCF-7 cells, following treatment with $25 \mu \mathrm{M}$ rhamnetin compared with the cells that were treated with $25 \mu \mathrm{M}$ alone. Jia et al (20) demonstrated that rhamnetin induced sensitization via miR-34a and the Notch-1 signaling pathway in hepatocellular carcinoma cells.

To the best of our knowledge, the present study was the first to demonstrate that treatment with rhamnetin was able to significantly inhibit cell proliferation, induce caspase-3/9 activity, promote the expression of p53 protein and miR-34a, and suppress the Notch1 expression in MCF-7 cells. Therefore, it was revealed that rhamnetin suppresses the growth of human breast cancer cells and may be used for clinical applications.

\section{Acknowledgements}

Not applicable.

\section{Funding}

No funding was received.

\section{Availability of data and materials}

The analyzed data sets generated during the present study are available from the corresponding author on reasonable request.

\section{Authors' contributions}

LaL designed the experiments; YW, ZP, BW, ZY, ZJ, LiL, CW and HT performed the experiments; $\mathrm{LaL}$ and $\mathrm{YW}$ analyzed the data and $\mathrm{LaL}$ wrote the manuscript.

\section{Ethics approval and consent to participate}

Not applicable.

\section{Patient consent for publication}

Not applicable.

\section{Competing interests}

The authors declare that they have no competing interests.

\section{References}

1. Tryfonidis K, Basaran G, Bogaerts J, Debled M, Dirix L, Thery JC, Tjan-Heijnen VC, Van den Weyngaert D, Cufer T, Piccart M, et al: A European organisation for research and treatment of cancer randomized, double-blind, placebo-controlled, multicentre phase II trial of anastrozole in combination with gefitinib or placebo in hormone receptor-positive advanced breast cancer (NCT00066378). Eur J Cancer 53: 144-154, 2016.

2. Dieras V, Wildiers H, Jassem J, Dirix LY, Guastalla JP, Bono P, Hurvitz SA, Gonçalves A, Romieu G, Limentani SA, et al: Trebananib (AMG 386) plus weekly paclitaxel with or without bevacizumab as first-line therapy for HER2-negative locally recurrent or metastatic breast cancer: A phase 2 randomized study. Breast 24: 182-190, 2015.

3. Yu J, Wang JG, Zhang L, Yang HP, Wang L, Ding D, Chen Q, Yang WL, Ren KH, Zhou DM, et al: MicroRNA-320a inhibits breast cancer metastasis by targeting metadherin. Oncotarget 7 : 38612-38625, 2016.
4. Mathe A, Scott RJ and Avery-Kiejda KA: MiRNAs and other epigenetic changes as biomarkers in triple negative breast cancer. Int J Mol Sci 16: 28347-28376, 2015.

5. He BS, Pan YQ, Lin K, Ying HQ, Wang F, Deng QW, Sun HL, Gao TY and Wang SK: Evaluation the susceptibility of five polymorphisms in microRNA-binding sites to female breast cancer risk in Chinese population. Gene 573: 160-165, 2015.

6. Bertoli G, Cava C and Castiglioni I: MicroRNAs: New biomarkers for diagnosis, prognosis, therapy prediction and therapeutic tools for breast cancer. Theranostics 5: 1122-1143, 2015.

7. Adams BD, Parsons C and Slack FJ: The tumor-suppressive and potential therapeutic functions of miR-34a in epithelial carcinomas. Expert Opin Ther Targets 20: 737-753, 2016.

8. Javeri A, Ghaffarpour M, Taha MF and Houshmand M: Downregulation of miR-34a in breast tumors is not associated with either $\mathrm{p} 53$ mutations or promoter hypermethylation while it correlates with metastasis. Med Oncol 30: 413, 2013.

9. Kato M, Paranjape T, Muller RU, Nallur S, Gillespie E, Keane K, Esquela-Kerscher A, Weidhaas JB and Slack FJ: The mir-34 microRNA is required for the DNA damage response in vivo in $\mathrm{C}$. Elegans and in vitro in human breast cancer cells. Oncogene 28: 2419-2424, 2009

10. Vogt M, Munding J, Gruner M, Liffers ST, Verdoodt B, Hauk J, Steinstraesser L, Tannapfel A and Hermeking H: Frequent concomitant inactivation of miR-34a and $\mathrm{miR}-34 \mathrm{~b} / \mathrm{c}$ by $\mathrm{CpG}$ methylation in colorectal, pancreatic, mammary, ovarian, urothelial, and renal cell carcinomas and soft tissue sarcomas. Virchows Arch 458: 313-322, 2011.

11. Sun H, Li K and Shen S: A study of the role of Notch1 and JAG1 gene methylation in development of breast cancer. Med Oncol 33: 35, 2016.

12. Cao YW, Wan GX, Sun JP, Cui XB, Hu JM, Liang WH, Zheng YQ, Li WQ and Li F: Implications of the Notch1-Snail/Slug-epithelial to mesenchymal transition axis for lymph node metastasis in infiltrating ductal carcinoma. Kaohsiung J Med Sci 31: 70-76, 2015.

13. Li XJ, Ji MH, Zhong SL, Zh QB, Xu JJ, Zhao JH and Tang JH: MicroRNA-34a modulates chemosensitivity of breast cancer cells to adriamycin by targeting Notch1. Arch Med Res 43: 514-521, 2012.

14. Bae Y, Yang T, Zeng HC, Campeau PM, Chen Y, Bertin T, Dawson BC, Munivez E, Tao J and Lee BH: miRNA-34c regulates Notch signaling during bone development. Hum Mol Genet 21: 2991-3000, 2012.

15. Bernardo BC, Gao XM, Winbanks CE, Boey EJ, Tham YK, Kiriazis H, Gregorevic P, Obad S, Kauppinen S, Du XJ, et al: Therapeutic inhibition of the miR-34 family attenuates pathological cardiac remodeling and improves heart function. Proc Natl Acad Sci USA 109: 17615-17620, 2012.

16. Jnawali HN, Lee E, Jeong KW, Shin A, Heo YS and Kim Y: Anti-inflammatory activity of rhamnetin and a model of its binding to c-Jun NH2-terminal kinase 1 and p38 MAPK. J Nat Prod 77: 258-263, 2014.

17. Ji SY, Choi KM, Lee YS, Yu JY, Shin DM, Lee S, Yoo KS, Lee YM, Yun YP and Yoo HS: Rhamnetin-induced suppression of clonal expansion during early stage of adipogenesis. Arch Pharm Res 35: 1083-1089, 2012.

18. Lee KP, Kim JE and Park WH: Cytoprotective effect of rhamnetin on miconazole-induced H9c2 cell damage. Nutr Res Pract 9: 586-591, 2015.

19. Mattarei A, Biasutto L, Rastrelli F, Garbisa S, Marotta E, Zoratti $\mathrm{M}$ and Paradisi C: Regioselective O-derivatization of quercetin via ester intermediates. An improved synthesis of rhamnetin and development of a new mitochondriotropic derivative. Molecules 15: 4722-4736, 2010.

20. Jia H, Yang Q, Wang T, Cao Y, Jiang QY, Ma HD, Sun HW, Hou MX, Yang YP and Feng F: Rhamnetin induces sensitization of hepatocellular carcinoma cells to a small molecular kinase inhibitor or chemotherapeutic agents. Biochim Biophys Acta 1860: 1417-1430, 2016.

21. Livak KJ and Schmittgen TD: Analysis of relative gene expression data using real-time quantitative PCR and the 2(-Delta Delta C(T)) method. Methods 25: 402-408, 2001.

22. Rajan SS, Sharma SC, Kumar N, Kumar R, Singh G, Singh R and Tomar P: Clinical and cosmetic results of breast boost radiotherapy in early breast cancer: A randomized study between electron and photon. J Cancer Res Ther 10: 889-895, 2014.

23. Zhao S, Chlebowski RT, Anderson GL, Kuller LH, Manson JE, Gass M, Patterson R, Rohan TE, Lane DS, Beresford SA, et al: Sex hormone associations with breast cancer risk and the mediation of randomized trial postmenopausal hormone therapy effects. Breast Cancer Res 16: R30, 2014. 
24. Mayer IA, Abramson VG, Isakoff SJ, Forero A, Balko JM, Kuba MG, Sanders ME, Yap JT, Van den Abbeele AD, Li Y, et al: Stand up to cancer phase Ib study of pan-phosphoinositide-3-kinase inhibitor buparlisib with letrozole in estrogen receptor-positive/human epidermal growth factor receptor 2-negative metastatic breast cancer. J Clin Oncol 32: 1202-1209, 2014.

25. Pieme CA, Santosh GK, Tekwu EM, Askun T, Aydeniz H, Ngogang JY, Bhushan S and Saxena AK: Fruits and barks extracts of Zanthozyllum heitzii a spice from Cameroon induce mitochondrial dependent apoptosis and G0/G1 phase arrest in human leukemia HL-60 cells. Biol Res 47: 54, 2014.

26. Yang S, Li Y, Gao J, Zhan T, Li S, Luo A, Chen H, Ding F, Wang X and Liu Z: MicroRNA-34 suppresses breast cancer invasion and metastasis by directly targeting Fra-1. Oncogene 32: 4294-4303, 2013.

27. Kang J, Kim E, Kim W, Seong KM, Youn H, Kim JW, Kim J and Youn B: Rhamnetin and cirsiliol induce radiosensitization and inhibition of epithelial-mesenchymal transition (EMT) by miR-34a-mediated suppression of Notch-1 expression in non-small cell lung cancer cell lines. J Biol Chem 288: 27343-27357, 2013.

28. Ng WL, Chen G, Wang M, Wang H, Story M, Shay JW, Zhang X, Wang J, Amin AR, Hu B, et al: OCT4 as a target of miR-34a stimulates p63 but inhibits p53 to promote human cell transformation. Cell Death Dis 5: e1024, 2014.

29. Huang SM, Tsai CF, Chen DR, Wang MY and Yeh WL: p53 is a key regulator for osthole-triggered cancer pathogenesis. Biomed Res Int 2014: 175247, 2014.
30. Hargraves KG, He L and Firestone GL: Phytochemical regulation of the tumor suppressive microRNA, miR-34a, by p53-dependent and independent responses in human breast cancer cells. Mol Carcinog 55: 486-498, 2016.

31. Peng D, Tanikawa T, Li W, Zhao L, Vatan L, Szeliga W, Wan S, Wei S, Wang Y, Liu Y, et al: Myeloid-derived suppressor cells endow stem-like qualities to breast cancer cells through IL6/STAT3 and NO/NOTCH Cross-talk Signaling. Cancer Res 76: 3156-3165, 2016.

32. Cui J, Li P, Liu X, Hu H and Wei W: Abnormal expression of the Notch and Wnt/ $\beta$-catenin signaling pathways in stem-like ALDHCD44 cells correlates highly with Ki-67 expression in breast cancer. Oncol Lett 9: 1600-1606, 2015.

33. Portanova P, Notaro A, Pellerito O, Sabella S, Giuliano M and Calvaruso G: Notch inhibition restores TRAIL-mediated apoptosis via AP1-dependent upregulation of DR4 and DR5 TRAIL receptors in MDA-MB-231 breast cancer cells. Int J Oncol 43: 121-130, 2013.

34. Pamarthy S, Jaiswal MK, Kulshreshtha A, Katara GK, Gilman-Sachs A and Beaman KD: The Vacuolar ATPase a2-subunit regulates Notch signaling in triple-negative breast cancer cells. Oncotarget 6: 34206-34220, 2015.

35. Shao S, Zhao X, Zhang X, Luo M, Zuo X, Huang S, Wang Y, $\mathrm{Gu} S$ and Zhao $\mathrm{X}$ : Notch1 signaling regulates the epithelial-mesenchymal transition and invasion of breast cancer in a Slug-dependent manner. Mol Cancer 14: 28, 2015.

36. Yang H, Li Y, Li T, Xu M, Chen Y, Wu C, Dang X and Liu Y: Multifunctional core/shell nanoparticles cross-linked polyetherimide-folic acid as efficient Notch-1 siRNA carrier for targeted killing of breast cancer. Sci Rep 4: 7072, 2014. 